\title{
The effects of earlier surgery and shorter bedrest on the outcome in patients with subarachnoid haemorrhage
}

\author{
SEPPO JUVELA, * MARKKU KASTE, $\dagger$ MATTI HILLBOM $\dagger$ \\ From the Departments of Neurosurgery, ${ }^{*}$ and Neurology, $\uparrow$ University of Helsinki, Finland
}

SUMMARY The effects of earlier surgery and shorter bedrest on the outcome in 338 consecutive patients with subarachnoid haemorrhage admitted within five years to a primary emergency hospital were evaluated. Mortality from rebleeds diminished more than surgical mortality increased. Shortened bedrest did not increase the number of rebleeds in patients not operated on. The combined mortality from rebleed and surgery decreased by $32 \%$ and the overall mortality by $21 \%$.

There is no general agreement about the optimal time of surgery or the length of bedrest in patients with subarachnoid haemorrhage (SAH) treated conservatively.'

We analysed the effects of earlier surgery and shorter bedrest on the outcome of patients with SAH.

\section{Patients and methods}

Three hundred and thirty-eight consecutive patients, aged 15-55 years, who were admitted to the Meilahti Hospital, University of Helsinki, in the five year period 1977-81 because of primary subarachnoid haemorrhage were included in the study. SAH was verified by at least one atraumatic lumbar puncture and/or by computer tomography (CT) or at necropsy. We excluded patients with a previous $\mathrm{SAH}$, arteriovenous malformations, trauma or who were admitted later than 72 hours from the onset of symptoms.

The clinical state of the patients was determined on admission according to Botterell's classification ${ }^{2}$ and the follow-up state, six months thereafter, according to the Glasgow Outcome Scale (GOS). ${ }^{3}$ The patients received a questionnaire and were interviewed by telephone concerning further SAHs, other possible

Address for reprint requests: S Juvela MD, Department of Neurosurgery, Helsinki University Central Hospital, Topeliuksenkatu 5, SF-00260 Helsinki 26, Finland.

Received 10 May 1988 and in final revised form 17 February 1989 illnesses, working capacity and independence in the activities of daily living (ADL). The follow-up infor- 8 mation was collected from all the patients during 1985 Death certificates and necropsy reports of all deceased patients were studied.

\section{Results}

The characteristics of the patients treated in 1977-78 and 1979-81 were similar (table).

Aneurysms were detected in men $(73.3 \%)$ and women $(66 \cdot 0 \%)$ with equal frequency.

The location of the ruptured aneurysm was as follows: $88(37 \%)$ in the anterior cerebral, $90(38 \%)$ in the middle cerebral, $45(19 \%)$ in the internal carotid and $13(6 \%)$ in the vertebrobasilar territories.

Thirty-nine per cent of all patients, $56 \%$ of the patients with a verified aneurysm and $67 \%$ of the patients with a verified aneurysm and surviving at least 48 hours, were operated on. More patients were operated on and the surgery was performed earlier at the end of the study compared with the beginning of study (table). The absolute bedrest of patients surviving at least three weeks was shortened (table).

Two hundred and seven patients $(61 \%)$ were treated conservatively of whom 108 survived at least 20 days. Eighty two of them did not have a verified aneurysm. No patient without an aneurysm had a rebleed. Seven of the 26 patients $(27 \%)$ with an aneurysm not operated upon had a fatal and one a non-fatal rebleed 
Table Characteristics and outcome of patients with subarachnoid haemorrhage according to the two treatment periods

\begin{tabular}{|c|c|c|c|}
\hline & $1977-78$ & $1979-81$ & $p$ value \\
\hline $\begin{array}{l}\text { Sex ratio (M:F) } \\
\text { Median age in years (range) }\end{array}$ & $\begin{array}{l}69: 58 \\
41(17-55)\end{array}$ & $\begin{array}{l}107: 104 \\
40(16-55)\end{array}$ & $\begin{array}{l}\text { NS* } \\
\text { NS } †\end{array}$ \\
\hline $\begin{array}{l}\text { Grade on admission } \\
\text { I-II } \\
\text { III } \\
\text { IV-V }\end{array}$ & $\begin{array}{l}79 / 127(62 \%) \\
22 / 127(17 \%) \\
26 / 127(21 \%)\end{array}$ & $\left\{\begin{array}{l}134 / 211(64 \%) \\
26 / 211(12 \%) \\
51 / 211(24 \%)\end{array}\right.$ & NS* \\
\hline $\begin{array}{l}\text { Angiograms } \\
\text { None } \\
\text { Unilateral carotid } \\
\text { Bilateral carotid } \\
\text { Panangiography }\end{array}$ & $\begin{array}{l}36 / 127(28 \%) \\
5 / 127(4 \%) \\
79 / 127(62 \%) \\
7 / 127(6 \%)\end{array}$ & $\begin{array}{l}39 / 211(19 \%) \\
9 / 211(4 \%) \\
125 / 211(59 \%) \\
38 / 211(18 \%)\end{array}$ & $<0.01^{*}$ \\
\hline $\begin{array}{l}\text { Localisation of aneury } \\
\text { anterior region } \\
\text { VBA } \\
\text { unknown } \\
\text { no aneurysm }\end{array}$ & $\begin{array}{l}76 / 127(60 \%) \\
3 / 127(2 \%) \\
44 / 127(35 \%) \\
4 / 127(3 \%)\end{array}$ & $\begin{array}{l}147 / 211(70 \%) \\
10 / 211(5 \%) \\
28 / 211(13 \%) \\
26 / 211(12 \%)\end{array}$ & $\begin{array}{l}\text { NS* } \\
\text { NS* } \\
<0.001^{*} \\
<0.01^{*}\end{array}$ \\
\hline $\begin{array}{l}\text { Number of patients with } \\
\text { rebleeds }\end{array}$ & $34 / 127(27 \%)$ & $30 / 2$ & $=0.01^{*}$ \\
\hline $\begin{array}{l}\text { Surgically treated } \\
\text { Timing of operation (SD) }\end{array}$ & $\begin{array}{l}31 / 127(24 \%) \\
18(5 \cdot 2) \\
29(13)\end{array}$ & $\begin{array}{l}100 / 211(47 \%) \\
11(4.5)\end{array}$ & $\begin{array}{l}<0.001^{*} \\
<0.001 \dagger \\
<0.001 \dagger\end{array}$ \\
\hline $\begin{array}{l}\text { Cause of death at } \\
\text { six months }\end{array}$ & & & \\
\hline $\begin{array}{l}\text { Primary bleed } \\
\text { Rebleed } \\
\text { Surgery } \\
\text { Rebleed + surgery } \\
\text { Total mortality }\end{array}$ & $\begin{array}{l}24 / 127(19 \%) \\
26 / 103(25 \%) \\
0 / 31(0 \%) \\
26 / 103(25 \%) \\
50 / 127(39 \%)\end{array}$ & $\begin{array}{l}35 / 211(17 \%) \\
22 / 176(13 \%) \\
8 / 100(8 \%) \\
30 / 176(17 \%) \\
65 / 211(31 \%)\end{array}$ & $\begin{array}{l}\mathrm{NS}^{*} \\
<0 \cdot 01 \ddagger \\
\mathrm{NS} \ddagger \\
\mathrm{NS}^{*} \\
\mathrm{NS}^{*}\end{array}$ \\
\hline $\begin{array}{l}\text { Glasgow outcome scale at } \\
\text { six months } \\
\text { Independent } \\
\text { Dependent } \\
\text { Dead }\end{array}$ & $\begin{array}{l}68 / 127(54 \%) \\
9 / 127(7 \%) \\
50 / 127(39 \%)\end{array}$ & $\begin{array}{l}130 / 211(62 \%) \\
16 / 211(8 \%) \\
65 / 211(31 \%)\end{array}$ & NS $^{*}$ \\
\hline
\end{tabular}

NS $=$ not significant

${ }^{*}$ Chi-square test; †Mann-Whitney’s $U$ test; †Fisher’s exact 2-tail test.

panangiography $=$ bilateral carotid and vertebral angiograms; anterior region $=$ the anterior part of the Circle of Willis; $\mathrm{VBA}=$ vertebrobasilar artery; unknown = patients without panangiography or necropsy; no aneurysm = patients with panangiography or necropsy; Independent = minimally or moderately disabled; Dependent $=$ severely disabled or vegetative.

later than 20 days after the primary bleed. Three of the fatal rebleeds occurred during bedrest and four after mobilization (one on the 4th and three on the 5th week). Two conservatively treated patients had a rebleed at 2 and 3 years.

The decrease in rebleed mortality was significant but not the increase in surgical mortality (table). Consequently the combined mortality from rebleed and surgery decreased by $32 \%$. A $21 \%$ decrease in overall mortality was also observed (from $39 \%$ to $31 \%$ ).

Rupture of basilar artery aneurysms caused the greatest mortality (Fisher 2-tail $p=0.004$ ). Nine of the 11 patients with basilar aneurysms died while being treated conservatively and so did the only one treated surgically. Bleeding from aneurysms of the middle cerebral artery (MCA) were more often fatal during the first two days than from other aneurysms (Fisher 2-tail $p=0.0024$ ) probably because of an expansive intracerebral haematoma.

There were less late rebleeds in the life table analysis computed according to the day of the first rebleed among the patients treated in the years 1979-81
(Breslow's stat $=7.41, \mathrm{df}=1, \mathrm{p}<0.01$ ). In this analysis data were used up to the time of the first rebleed, to death, to operation or to the end of 6 months follow up. The decrease in rebleeds was most prominent later than 12 days after the onset of SAH.

There was no change in postoperative morbidity during the study. Nine per cent of the patients had severe, and $12 \%$ mild to moderate postoperative neurological deficits.

At six months follow-up the morbidity of the patients did not differ according to the year of treatment, sex or age. The same held true after a follow-up of 3-5 years. Seventy-nine per cent of patients surviving six months had a good outcome, $9 \%$ were moderately disabled and $12 \%$ were severely disabled or in a vegetative state.

ADL evaluated at two years was not influenced by the year of treatment. Eighty-seven per cent of patients were independent, 9\% required some assistance in ADL and $4 \%$ were totally disabled.

\section{Discussion}

More patients were operated on and surgery was performed earlier in the later part of the study which was followed by a significant decrease in rebleed mortality.

Although surgical mortality increased when patients were operated on earlier (a well known fact also from earlier studies) ${ }^{4}$ the combined mortality from rebleeds and surgery decreased by $32 \%$. Furthermore the overall mortality decreased by $21 \%$.

The shorter bedrest in patients treated conservatively was not followed by an increase in rebleeds or rebleed mortality during the hospital stay or the follow-up. Partly, this can be explained by a more active policy, less aneurysms were left unoperated. None of the patients without a proved aneurysm suffered a rebleed. Accordingly bedrest shorter than 3 weeks seems to be a realistic choice for such patients.

Although the patients were operated on earlier it did not increase their morbidity. This may be explained by our relative conservative policy; only patients in Botterell's grades I-II were operated upon at, on average, 11 days at the end of the study.

\section{References}

1 Marsh H, Maurice-Williams RS, Lindsay KW. Differences in the management of ruptured intracranial aneurysms: a survey of practice amongst British neurosurgeons. J Neurol Neurosurg Psychiatry 1987;50:965-70.

2 Botterell EH, Lougheed WM, Scott JW, Vandewater SL. Hypothermia, and interruption of carotid, or carotid and vertebral circulation, in the surgical management of intracranial aneurysms. J Neurosurg 1956;13:1-42.

3 Jennett B, Bond M. Assessment of outcome after severe brain damage. A practical scale. Lancet $1975 ; \mathbf{i}: 480-4$.

4 Sundt TM Jr, Kobayashi S, Fode NC, Whisnant JP. Results and complications of surgical management of 809 intracranial aneurysms in 722 cases. Related and unrelated to grade of patient, type of aneurysm, and timing of surgery. $J$ Neurosurg 1982;56:753-65. 